\title{
Imaging of Molecular Dynamics Regulated by Electrical Activities in Neural Circuits and in Synapses
}

\author{
Ritsuko Fujii ${ }^{a, b}$ Michinori Ichikawac Miwako Ozaki ${ }^{\mathrm{a}-\mathrm{d}}$ \\ aWaseda-Olympus Bioscience Research Institute, Waseda University, Singapore; ${ }^{b}$ Advanced Research Institute for \\ Biomedical Science, Tokyo, 'Brainvision Inc., Tokyo, and d Institute for Biomedical Engineering, Waseda University, \\ Tokyo, Japan
}

\section{Key Words}

Activity-dependent synaptic events - Neural circuits • Synapses $\cdot$ Molecular imaging $\cdot$ Neuron glia interaction $\cdot$ Voltage-sensitive dye

\begin{abstract}
One of the major challenges in brain research is to unravel a network of molecules, neurons, circuits and systems that are responsible for dynamic and hierarchical brain functions. To understand molecular events that occur in synapses could be an important key to exploring the mechanism of information processing. A spatiotemporal recording method is required to observe neuronal activities in a particular local circuit and to resolve single synaptic potential with high resolution. As alternative methods, real-time imaging using fluorescent probes and optical recording methods are also a powerful approach for investigating the molecular dynamics of biological events in neurons in vitro and in vivo. Recently, optical imaging techniques have become of great importance to visualize the molecular dynamics in a micronsized compartment of a single neuron such as neuronal synapse. In general, the presynaptic axon forms synapses at the postsynaptic site on the dendritic spines in the mammalian central nervous system. Subsets of the synapses undergo a series of enduring changes in spine shape and density as well as alterations in electrophysiological functions. Here we
\end{abstract}

describe recent optical imaging studies conducted by elaborate methods and techniques that provide evidence for the link between neural activity and molecular dynamics.

Copyright ๑ 2008 S. Karger AG, Basel

\section{Introduction}

The entity of our higher order functions is a network comprised of neurons that are interconnected by different patterns of electrical activity. In fact, the deep brain stimulation with electric stimuli, which is frequently used as medical treatment for motor disorders and in recent years for mental disorders, aims to balance the electrical activities between neural circuits. The electrical treatment alleviates even complicated psychiatric symptoms apparently caused by impaired higher order functions like psychological illness. Neuronal function is often referred to as 'phenomena' brought about by neuronal electric signals and/or connectivity of circuits. If it can be defined as more essential terms such as 'substance' that is quantitative and qualitative of genes or molecules, collaboration between biologists, physicists, or chemists with diverse expertise will accelerate discovery of the drug target and the drug development for neuronal disorders. The neural network should be accurately understood to clarify the molecular mechanism of patterning

\section{KARGER}

Fax +4161306 1234 E-Mail karger@karger.ch www.karger.com
(ㄷ) 2008 S. Karger AG, Basel

$1424-862 X / 08 / 0164-0260 \$ 24.50 / 0$

Accessible online at:

www.karger.com/nsg
Dr. Miwako Ozaki

Waseda-Olympus Bioscience Research Institute

Waseda University, 11 Biopolis Way, Helios \#05-01/02

Singapore 138667 (Singapore)

Tel. +65 6478 9721, Fax +65 6478 9416, E-Mail mozaki@waseda.jp 
of the electric activity. In addition, the spatiotemporal information of the electric activities should be examined in conjunction with the neural circuits. Imaging techniques have been established as very powerful methods for research on neural circuits of whole animal brain. However, it is still required to understand timing and combination of differential stimulation entries to the circuits, even in the analyses of intracellular signaling. It is also important to understand the entire sequences of signal activation in the signal transduction pathway involved in neural information processing and to acquire two- or three-dimensional information of signal transduction. Such spatiotemporal signaling information in the information-processing system will be of great benefit toward treatment for neuronal disorders. Herein we describe activity-dependent molecular events that occur in synapses that play key parts for information processing and imaging technology to determine activity-dependent phenomena.

In order to accomplish innovative drug development related to signal transfer (herein the term is used in a broad meaning including all synaptic events like signal transduction reaction, local transcription, local translation, molecular motility, and so on), particularly for brain disorders ascribed to aberrant information processing, a breakthrough is required from each aspect to overcome the above issues. For example, it is necessary to: (1) identify neural network entities (hardware information); (2) obtain spatiotemporal information with the use of imaging methods, and (3) find a spatiotemporal analysis method that uses simulation and a theory based on enough knowledge of physiology and in keeping with the viewpoint of information processing.

In this review, we highlight molecular biological phenomena in neuronal synapses and neuron-glia interaction. Neuronal synapses in a single neuron are integral units of neural circuits in the brain. Neurons in the mammalian central nervous system (CNS) are highly polarized cells with axons and dendrites which extend from the cell body. Dendrites bear small protrusions $(0.5-2 \mu \mathrm{m}$ in length) called dendritic spines along the dendritic shafts which serve as postsynaptic compartments for the majority of glutamatergic excitatory inputs [1]. Live imaging studies have shown that dendritic spines are remarkably dynamic and rapidly change size and shape to integrate and modulate the synaptic activity for the proper synaptic connectivity [2-4]. Besides the dynamic motility, dendritic spines contain a distinct structure and organelles called postsynaptic density (PSD), which are continuously reorganized depending on the strength of synaptic inputs (fig. 1) [5]. Accumulating molecular studies on PSD have corroborated signal transduction molecules that regulate the actin cytoskeleton and its binding proteins within the dendritic spines [6]. It has been widely accepted that the synaptic plasticity could be attributed to the ability of postsynapses, which can control synaptic excitability and integrate diverse patterns of synaptic activity.

The presence of mRNAs and protein synthesis machinery such as polyribosomes in the dendritic spines strongly supports the idea that synaptic plasticity is partially regulated by local protein synthesis only at the specific synapses or individual spines [7-9]. Morphological changes of dendritic spines should be subjected to rapid alteration by patterns of neuronal activity and postsynaptic glutamate receptor activation. These processes are initiated by posttranslational modification of preexisting synaptic proteins, for instance phosphorylation or dephosphorylation, while long-term synaptic plasticity, such as long-term potentiation (LTP) and long-term depression (LTD), has been shown to require de novo protein synthesis in neuronal dendrites $[10,11]$. However, the precise molecular dynamics induced by synaptic activation have remained elusive. Together with genetic and biochemical approaches, recent progress in optical imaging studies has unraveled an unexpected mechanistic link between the synaptic activity and the modification of the excitatory postsynaptic compartment. Furthermore, on neural circuit development/remodeling, the roles of glial cells are crucial and neuron-glia interaction was particularly highlighted from a recent study [our present work; also see Stevens, this issue].

Real-time in vivo imaging is an emerging field in biomedical research. Optical imaging techniques are especially of great interest since their high resolution provides more precise spatiotemporal information of biological and physiological processes at the molecular level. Nonetheless, optical live-imaging techniques have important implications for drug discovery and development, and also diagnosis of diseases. Progress in the development of various fluorescent dyes in past years has now enabled us to monitor the neuronal activation in particular neurons or brain areas in vivo. Thus, the function or dysfunction of neural circuits, which underlie emotional behavior or pathology of neuronal disorders, could be monitored by elaboration of in vivo optical imaging. The techniques to visualize behavior of molecules in experimental systems at the cellular level and in vivo are described by Qiu et al. in this issue. Furthermore, a simulation method for analysis of signal transduction was introduced in the cerebellar system as an example, for which there was well-accumulated network information. Ogasawara et al. intro- 


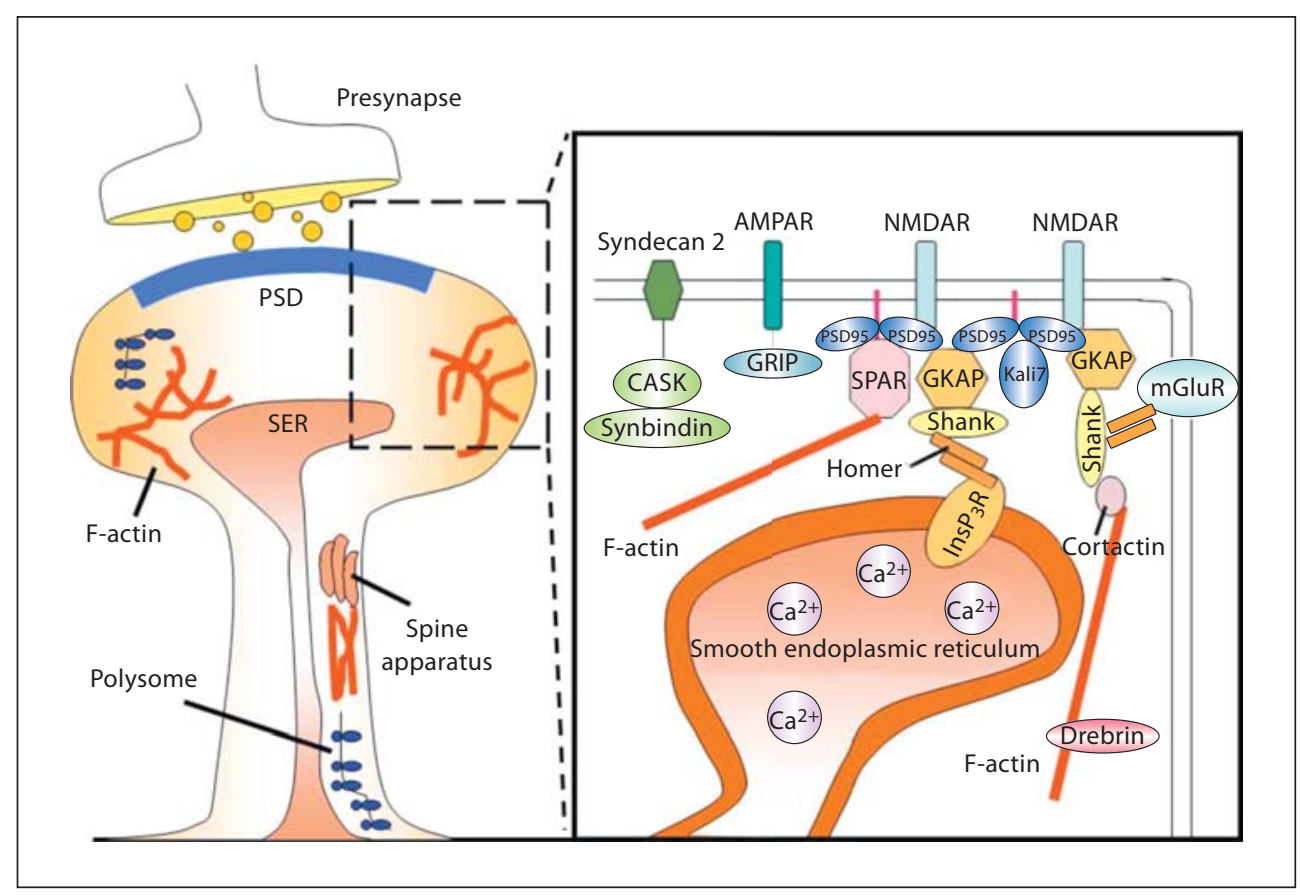

Fig. 1. Molecular structure of the dendritic spine. Mushroomtype spines are observed at excitatory postsynapses of neurons in the CNS. In the spine heads, the postsynaptic density (PSD) is found at the synaptic junction and apposed to the presynaptic active zone. Dendritic spines contain various small organelles such as smooth endoplasmic reticulum (SER), which functions, at least in part, as a calcium store from which calcium ions are released in response to synaptic stimulation. There are also spine apparatuses that are implicated in repository or relay of membrane protein trafficking from or to the synapses. In PSD there are glutamate receptors associated with PSD proteins including PSD95, GKAP, Shank, Homer, GRIP, or SPAR. Spines are abundant of actin filament which is associated with glutamate receptors through the interaction with SPAR or Cortactin, and may play a crucial role in synaptic remodeling. Polysomes are detected in the

duce theoretical studies of cerebellar LTD and simulation of neuronal signal transduction and signal transmission of $\mathrm{Ca}^{2+}$ wave transmission and signal transduction pathways in the network. Finally, by using three-dimensional structural analysis of protein, drug design of small compounds is possible and this is one strategy of drug discovery for fine-tuning of neural transmission and signal transduction in the neural network. Yoon et al. describe such an example in this issue.

In this review, we focus on recent advances in optical fluorescent imaging approaches to visualize the activitydependent molecular dynamics in excitatory postsynapses of individual neurons, and also describe voltagesensitive dye (VSD) techniques that have made a great spine shafts and the base of spines, and contain rRNAs and ribosomal proteins suggesting that they provide the site for local translation of dendritic mRNAs that are brought to the spines. The enlarged box illustrates PSD proteins and protein-protein interactions with the PSD. GRIP (glutamate-receptor-interacting protein), and CASK (calcium/calmodulin-dependent serine protein kinase) and synbindin, are PDZ-containing scaffold proteins that bind to AMPA ( $\alpha$-amino-3-hydroxy-5-methyl-4-isoxazole propionic acid) receptors and syndecan 2, respectively. AMPAR $=$ AMPA receptor; F-actin $=$ filamentous actin; GKAP $=$ guanylate-kinase-associated protein; Kali7 $=$ Kalirin-7; $\mathrm{mGluR}=$ metabotropic glutamate receptor; NMDAR $=N$-methyl-D-aspartate receptor; SPAR = spine-associated RapGAP. Adapted from Hering and Sheng [6].

contribution to in situ monitoring of the neuronal excitation in both local neuronal circuits and specific brain areas in the last decade. We hope to highlight the trends in high-resolution optical imaging and its applications to explore the neural activity-dependent molecular localization, structural changes, and signal transduction.

\section{Observation of Activity-Dependent Synaptic Events by Imaging Technologies}

Neuronal synapse is a basic functional compartment that converges and transmits the complicated neuronal signals in the neural circuits $[1,5,12]$. Recent studies have 
demonstrated that the synapses undergo rather diverse events to fine-tune the neuronal inputs and maintain their normal functions. Here we describe the progress in imaging of neuronal activity-dependent synaptic events to provide further insight into the dynamic neural circuits.

\section{Imaging of RNA Transport to the Dendrites}

\section{Transport of $m R N A$ to the Neuronal Dendrites}

The dendrite-targeted mRNAs are subjected to selective and specific local protein synthesis which is critical for persistent synaptic modifications such as LTP or LTD. Eberwine et al. [8] identified over 400 mRNAs as dendritic mRNAs in mechanically-harvested dendrites of cultured hippocampal neurons, including mRNAs for activity-regulated cytoskeleton associated protein (Arc), brain-derived neurotrophic factor (BDNF), $\mathrm{Ca}^{2+} / \mathrm{calmod}^{-}$ ulin kinase II (CaMKII) or microtubule-associated protein 2 . They also estimated that there must be $\sim 10,000$ different mRNAs expressed in the cell body of the same hippocampal neuron cultures, indicating that the dendritic transport of mRNAs is quite selective.

Transport of mRNAs to the dendrites from the cell body depends on RNA-binding proteins which transport specific sets of mRNAs to the dendrites. Nonetheless, the selection of mRNAs targeted to the dendrites should take place immediately after transcription and splicing. This process could therefore be attributed to the functions of RNA-binding proteins which can recognize the specific sequence in 3'UTR of these mRNAs [13-16]. For example, the mRNA-binding protein zipcode-binding protein 1 (ZBP) [17] specifically recognizes and binds to a 54-nucleotide in the $3^{\prime}$ UTR of $\beta$-actin mRNA, the so-called 'zipcode sequence' [18] (ZBP is a member of the heterogenous nuclear ribonucleoprotein (hnRNP) family of proteins that also includes hnRNA A2 and fragile X mental retardation protein (FMRP)). Like ZBP1, RNA and translocated liposarcoma (TLS) [19] have been shown to participate in nucleocytoplasmic shuttling of mRNAs in cultured neurons. In neurons, ZBP and $\beta$-actin mRNA are localized to both dendrites and axons [18] in response to activation of $N$-methyl-D-aspartate receptor (NMDA) receptors (NMDAR) and neurotrophins [20]. The delivery of newly synthesized mRNAs to the dendrites occurs in a motile structure called RNA granules [21, 22], which is a large messenger ribonucleoprotein complex (mRNP) now called $1000 S$ RNA granules composed of RNA-binding proteins and including Staufen [23, 24], FMRP [25, 26], hnRNP-U,
SYCRIP, TLS [19] and Aly/REF mRNA [27], mRNAs for CaMKII and Arc, and ribosomal RNAs [16]. There is no doubt that 1000S RNA granules are critically involved in the transport and translation of mRNAs in dendrites [22, 28] and transported to the dendrites by microtubule-based motor protein kinesin superfamily $5[27,28]$.

\section{Imaging of Messenger Ribonucleoprotein Complex}

The live-cell imaging of RNA granules can be achieved by high-resolution fluorescent microscopy using SYTO nucleic acid dyes (e.g. SYTO14) or green fluorescent protein (GFP)-fused RNA-binding protein [29]. Compared to fluorescent in situ hybridization, these methods heavily rely on a RNA-protein complex formation of considerable size. GFP is a relatively small and compact protein with a single domain structure $[30,31]$ which has almost no interference to native proteins. Endogenous RNA granules or RNA pool in the dendrites can also be detected by SYTO14. Although the dye discriminately binds to RNA, it has high permeability to cell membranes, high molar absorptivity, and extremely low intrinsic fluorescence.

Kiebler's group [32] nicely demonstrated the timelapse recording of the Staufen-GFP and SYTO14 using the different set of filters which separate the SYTO14 bound to RNA (521 nm, EM $547 \mathrm{~nm}$ ) from residual SYTO14 signals that are trapped through an EGFP filter set. RNA particles containing Staufen-GFP move along the dendrites at an average speed of $6.4 \mu \mathrm{m} / \mathrm{min}$, which is slower by one magnitude order than the fast axonal transport $(278 \mu \mathrm{m} / \mathrm{min})$. Movement of dendrite-specific mRNAs BC1 or Arc mRNA was previously rated at 4-5 $\mu \mathrm{m} / \mathrm{min}$ by fluorescent in situ hybridization of fixed neuronal dendrites [33]. The SYTO14 cluster by itself was measured to move in the dendrites at a speed of $\sim 6 \mu \mathrm{m} /$ min, which was similar to the velocity of movement of Staufen-GFP and RNA granule-containing dendritespecific mRNAs (4-6 $\mu \mathrm{m} / \mathrm{min})$. Thus, both GFP- and SYTO14-labeled RNA granules move along the dendrites in a similar mode. Although SYTO14 non-specifically binds to RNA and so labels the RNA granules independent of degradation [33], SYTO dyes are still an attractive solution to trace the movement of RNA granules in the dendrites with its convenience and stability.

Activity-Dependent mRNA Transport to the Dendrites and the Dendritic Spines

How might synaptic activity be involved in selective RNA transport to the dendrites? We have demonstrated that TLS-containing RNA granules are transported to the dendrites by potassium-induced depolarization and 


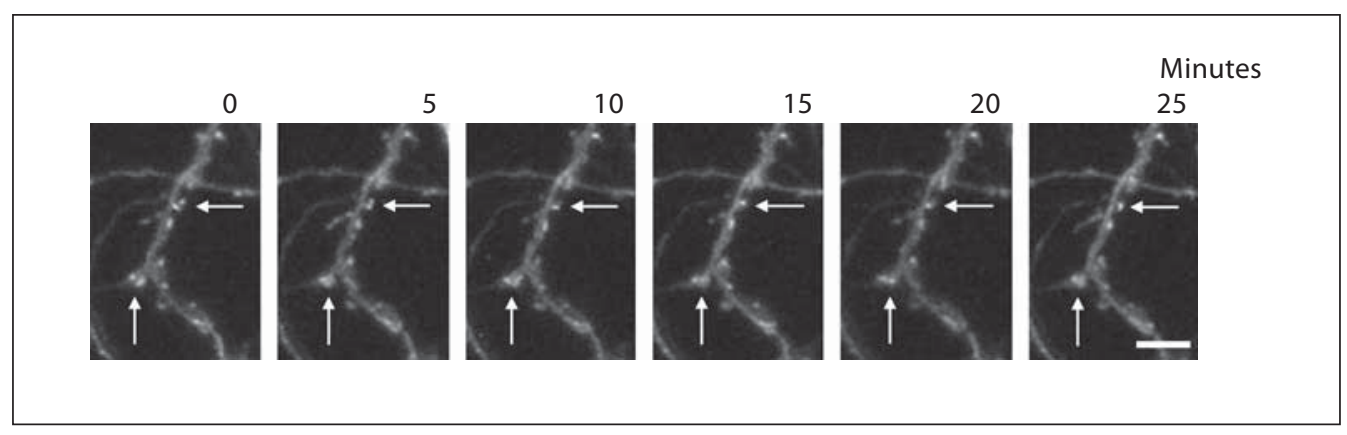

Fig. 2. Time-lapse monitoring of TLS-GFP in cultured hippocampal neurons. TLS-GFP was expressed in mouse-cultured hippocampal pyramidal neurons at 23 DIV. At this stage, cultured hippocampal pyramidal neurons develop mature spines along the dendrites and form synaptic connections with other neurons in vitro. TLS-GFP was found as large GFP clusters in the dendrites and also within the dendritic spine heads (arrows).
Movement of TLS-GFP was monitored over the time points by a confocal laser-scanning microscope (Olympus). Multiple optical images (4-10 slices, $\mathrm{z}$-axis: $0.5 \mu \mathrm{m}$ ) spanning $2-5 \mu \mathrm{m}$ along the $\mathrm{z}$-axis were combined by using Metamorph image analysis software. TLS-GFP was rapidly recruited into the spine heads from the dendritic shaft and excluded within $8-15 \mathrm{~s}$ in culture. Scale bar $=5 \mu \mathrm{m}$.
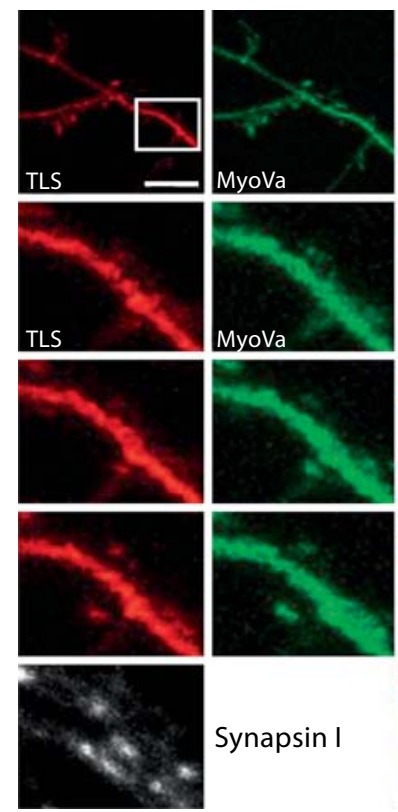

Synapsin I

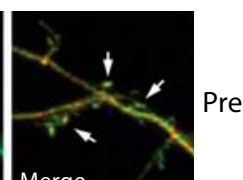

Merge
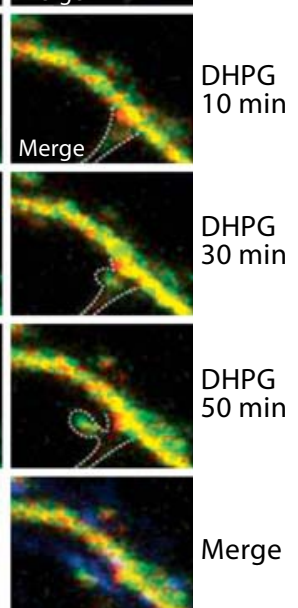

Fig. 3. Myosin-Va and TLS dynamics in dendritic spines. Two-color real-time imaging of TLS-RFP and Myosin-Va-GFP (MyoVa) showed that both proteins moved together into the same protrusion extended from the dendritic shaft in response to type I mGluR activation by mGluR agonist DHPG [(R,S)-3,5-dihydroxyphenylglycine]. The protrusion presented spine morphology and respective immunostaining with anti-synapsin I antibody revealed that the spine formed the synapse. Images shown are projections assembled from confocal optical sections at the indicated time points. Lower panels show enlarged images of the white rectangular area shown in the upper left panel. Dashes lines indicate the outline of the dendrites. Scale bar $=5 \mu \mathrm{m}$.

mGluR stimulation. TLS-containing RNA granules move bidirectionally along the dendrites of cultured hippocampal neurons at a velocity of $6-12 \mu \mathrm{m} / \mathrm{min}$ [19] (fig. 2). The most unique property of TLS is that it is recruited to the dendrites not only via microtubules, but also via actin filaments, suggesting that not only kinesin superfamily 5, but also the actin-dependent myosin motor may participate in proper targeting of mRNA and associated proteins in the dendrites and dendritic spines [27]. Our twocolor live monitoring captured the recruitment of TLS with a brain-specific myosin, Myosin-Va [34], into the dendritic spines that is regulated by mGluR 5 activation at postsynapses [35] (fig. 3). Our findings provide a clue to understanding the functional link between RNA transport to the dendritic spines and actin dynamics regulated by mGluR activation at the postsynapses. Hippocampal pyramidal neurons of TLS knockout mice display an abnormal spine morphology characterized by reduced spine density, reduced number of mature spines, and abnormal dendrite-branching patterns [19]. In response to mGluR5 signals, TLS targets the RNA granules to dendritic spines and in turn, the increase in calcium influx induced by mGluR5 activation triggers a release of TLS-containing RNA granules from Myosin-Va, followed by the translation of mRNAs which encode proteins required for synaptic remodeling or maintenance [36]. Phenotypes of spine morphology in TLS-deficient hippocampal neurons thus may reflect the loss of synaptic remodeling or synaptic maintenance through $\mathrm{Ca}^{2+}$ signaling, which can be monitored by calcium sensors described by Qiu et al. in this issue. 
Activity-Dependent Regulation of Local Translation in the Dendritic Spines

FMRP, an RNA-binding protein in mRNP, is quite unique with regard to its trafficking patterns, its target RNAs and its biological function in translational regulation in response to synaptic signals. The role for FMRP in RNA transport to the dendrites and local translation at synapses has been well established [37-39]. The most striking function of FMRP is that absence or mutation of FMRP leads to fragile X syndrome, an X-linked dominant disorder and most frequent cause of inherited mental retardation. FMRP binds RNA homopolymers and about $4 \%$ of human fetal brain mRNAs including myelin basic protein mRNA, and interestingly its own mRNA [38]. FMRP protein acts as a translational repressor of specific mRNAs at synapses [40], including those encoding the cytoskeletal proteins Arc and microtubule-associated protein $1 \mathrm{~B}$, and CaMKII $\alpha$. FMRP also directly binds to a small dendritic non-translationable RNA, BC1 (a polymerase III RNA transcript) in RNA granules [41]. It is known that translation of mRNAs with a sequence complementary to $\mathrm{BC} 1 \mathrm{RNA}$ is interfered by base-pairing with synaptic $\mathrm{BC} 1$ by FMRP. The pathology in the brain of both the fragile $\mathrm{X}$ mental retardation patients and FMRP (or FMR1) knockout mice appears to be limited to abnormalities in dendritic spines [26,37], suggesting that impaired regulation of mRNA localization and translation may affect spine maturation or synaptic pruning. Although dendritic localization of FMRP is facilitated after stimulation of either $\alpha$-amino-3-hydroxy-5-methylisoxazole-4-propionic acid (AMPA) receptor (AMPAR) or mGluR activation, mGluR5 activation may play a critical role in the dynamic trafficking of FMRP and Fmrl mRNA in the dendrites and at synapses [39].

Taken together, these studies on RNA-binding proteins in the neuronal dendrites suggest that mGluR and NMDAR signals may regulate a recruitment of distinct mRNA target to the RNA granules or different steps of the mRNA localization and synaptic translation.

\section{Imaging of Local Protein Synthesis}

\section{Detection of Local Protein Synthesis}

Local synaptic modification is thought to be responsible for the long-term plasticity in the nervous system $[42,43]$. Local protein synthesis in the spines has been proposed to underlie various forms of synaptic plasticity such as neurotrophin-induced potentiation in the hippocampus or mGluR-mediated enhancement of LTP $[10$,
44]. A neurotrophic factor, BDNF, has been shown to stimulate protein synthesis in translational-active region in the dendrites which is found near the synaptic sites [45]. When the GFP-reporter construct that contains the 3'UTR cytoplasmic polyadenylation element of CaMKII $\alpha$ mRNA is expressed in cultured hippocampal neurons, the translation of the GFP-reporter for CaMKII $\alpha$ is stimulated by activation of NMDAR in the translational-active region in the dendrites $[13,14]$. Time-lapse imaging of the newly synthesized GFP in the dendrites shows that BDNF increases the translation of the GFP-reporter for CaMKII $\alpha$ mRNA [45]. Even in mechanically isolated dendrites, BDNF stimulates translation of the GFP reporter. Recently, AMPARs were shown to be synthesized in dendrites in response to synaptic stimulation $[46,47]$ by mGluR activation, and also the depolarization with $\mathrm{KCl}$ increases the synthesis of both GluR1 and GluR2. The most recent quantitative fluorescence in situ hybridization by Grooms et al. [47] has shown that a substantial fraction of synaptic sites in hippocampal neurons contain GluR2 mRNA fluorescent clusters, which is consistent with strategic positioning and availability of on-site protein synthesis. Bidirectional regulation of dendritic AMPAR mRNAs is a novel mechanism for long-term modifications of glutamate receptor composition, and the number involved is potentially important for longlasting changes in synaptic efficacy [47]. As described in many reports, a short sequence tag can be delivered to the dendrites, however transport and translation of the full length of mRNAs encoding postsynaptic proteins were not successfully monitored in dendrites of living neurons. One possible explanation is that probably the full mRNAs are susceptible to degradation in the dendrites unless they are tightly bound to their vehicle proteins and folded into a RNA granule in the cell body until they reach their final destination to be unfolded and translated $[48,49]$. This mechanism may be suitable for the local translational system to avoid a 'traffic jam' at the polyribosomes in dendritic spines because quantitative electron microscopy revealed that spine synapses have only one or two polyribosomes, suggesting that they can translate only one or two mRNAs at a given time.

\section{Activity-Dependent Actin Dynamics in Postsynapses}

\section{Actin Dynamics in the Dendritic Spines}

Dendritic spines are quite motile and display diverse shapes, which might be correlated with synaptic strength $[2,50,51]$. They also rapidly alter their morphology by 
patterns of neuronal activity and postsynaptic glutamate receptor signals $[52,53]$. Since dendritic spines contain extremely high levels of actin and in fact the actin filament (F-actin) is the major cytoskeletal element in the spines [54], understanding the molecular mechanisms that control actin cytoskeleton of dendritic spines should provide insight into the structural plasticity of the postsynaptic compartment.

\section{Imaging of Synaptic Plasticity and Actin Dynamics}

Plasticity-dependent changes of actin dynamics lead to the arrangement and functional state of postsynaptic proteins, including neurotransmitter receptors, signaling molecules and scaffold proteins [52]. The morphological changes of spines or the formation of dendritic protrusions (or future spine outgrowth) occur in response to a variety of neural activities including electrical stimuli that evoke LTP. A critical role for F-actin in postsynaptic sites is implicated in the trafficking of AMPA-type glutamate receptors (AMPARs) at postsynaptic sites during LTP [55-59], which is assumed to be a typical form of synaptic plasticity. Moreover, actin dynamics are implicated in LTD [11], where de-anchoring of the A-kinase anchoring protein-protein kinase A complex from the PSD associated with F-actin remodeling triggers the endocytosis of AMPARs [60].

Elegant works by Okamoto et al. [61] showed the polymerization-depolymerization equilibrium of actin in living neurons of hippocampus slice culture. They monitored a rapid and persistent turnover and actin treadmill between two different forms of actin cytoskeletons globular (G-) actin and filamentous (F-) actin - in the spine heads. They successfully monitored the high-rate actin turnover in CA1 hippocampal pyramidal neurons by two-photon laser scanning microscopy and fluorescence resonance energy transfer (FRET)-based techniques using yellow fluorescent protein (YFP)-actin and cyan fluorescent protein (CFP)-actin [29], and showed that approximately $85 \%$ of the actin was exchanged within $2 \mathrm{~min}$. Actin polymerization and depolymerization are modulated rapidly in response to a wide range of frequencies of synaptic activities in accordance with potentiation or depotentiation of synaptic transmission. For example, LTP-induced tetanic stimulus shifts the F-actin/G-actin equilibrium towards polymerization (formation of $\mathrm{F}$ actin) while LTD-inducing low frequency stimulation ( $1 \mathrm{~Hz}, 15 \mathrm{~min}$ ) induced depolymerization (formation of G-actin). Interestingly, the shift in the F-actin/G-actin equilibrium occurs within $20 \mathrm{~s}$ after the stimulation, and persists in this state for at least another $30 \mathrm{~min}$, which was accompanied with either structural enlargement or shrinkage of dendritic spines that are observed for either the induction of LTP or LTD, respectively. The same structural basis of LTP of a single dendritic spine is associated with an increase in glutamate sensitivity of NMDAR mediated by an increase in AMPAR-mediated currents and activation of CaMKII [62]. These studies underpin a global consensus that actin dynamics in dendritic spines is critical for synaptic plasticity by which both postsynaptic structure and molecules are reversely reorganized. The increase in F-actin at postsynaptic sites in LTP is thought to provide additional binding sites for PSD protein, serve as a dynamic scaffold that tethers and stabilizes the translocated proteins [63].

\section{Synaptic Activity and Reorganization of Synaptic}

Structure

Despite the accumulating evidence for the importance of actin dynamics in synaptic plasticity [5,53], little is known about the mechanism by which actin is regulated by synaptic plasticity. A specific question here is how the induction of long-term synaptic plasticity affects the actin-based architecture in the dendritic spines. This gap may be partially bridged by a function of profilin, a small actin-binding protein implicated in stabilizing actin filaments. Profilin is targeted to spine heads when the postsynaptic NMDAR is activated, accompanied by concomitant blockage of actin-based morphological changes of spines [64]. NMDAR activation rapidly redistributes PSD proteins such as Homer [65], Shank [66] or cortactin [67] from spines to dendritic shafts that are physically linked to the actin cytoskeleton and NMDA/glutamate receptors at postsynapses [6]. However, they only appear to control accumulation of the receptors at the synaptic cleft through the actin-remodeling mechanism. Surprisingly, the targeting of profilin to dendritic spines is also triggered by electrical stimulation patterns known to induce the long-term changes in synaptic responsiveness associated with memory formation. However, both high-frequency mimicking titanic stimulation $(3 \times 1 \mathrm{~s}$ at $100 \mathrm{~Hz})$ and low-frequency stimulus pattern $(900$ pulses at $1 \mathrm{~Hz})$ trigger the profilin targeting [64]. This observation suggests that long-term changes in synaptic strength and profilin-dependent stabilization of synaptic morphology can in parallel be triggered by NMDAR activation, but that two events are mechanistically different. It is more likely that in addition to electrophysiological changes, NMDAR activation initiates changes in actin cytoskeleton in the dendritic spines that stabilize synaptic structure. 
Neuron-Glia Communication in Synaptic Modulation at Excitatory Synapses

\section{Neuron-Glia Interaction and Synaptic Functions}

Structural plasticity of the CNS is critical for brain function [68]. Recent studies have started unraveling the mechanisms of synaptic modulation by glial cells $[69,70]$. It is known that astrocytes not only control extracelullar neurotransmitter levels, but also buffer the extracellular ionic environment and propagate $\mathrm{Ca}^{2+}$ signals [71]. A vesicle-mediated mechanism has also been reported for the release of glial transmitters such as glutamate, ATP, Dserine, which can modulate synaptic function or connectivity [72]. In addition, electron microscopy has revealed an ultrastructure of a direct interaction between astrocytes and synapses in the hippocampus [73]. Interestingly, astrocyte processes are predominantly localized near the dendritic spines rather than in the presynaptic terminus. These findings suggest that astrocytic contact may induce local structural and functional modifications of dendrites or individual synapses [70].

\section{Imaging of Dynamics in Glia-Neuron Interactions}

Simultaneous morphological changes of neurons and glial cells actually take place in the brain. Structural changes in spines and astrocytes in the hippocampus also take place after LTP induction [59]. A recent study by Haber et al. captured the motility of astrocyte and neuronal dendrites in hippocampal slice culture by expressing GFP [30] and RFP [74] constructs to target astrocytes and neurons, respectively $[75,76]$. They unveiled the dynamic structural interplay between astrocytes and spines in which the astrocyte process extends towards a dendritic spine and continuously reorganizes the association with dendritic spines according to the changes in volume or shape of the spines, suggesting a concerted structural plasticity of astrocytes and neurons in a modulation of synaptic function.

\section{Synaptic Maturation and Remodeling by Glial Interaction}

The two-photon microscopic approach has been set to visualize a direct contact of astrocytes with postsynapses of pyramidal neurons in hippocampal slice cultures [77]. Two-color time-lapse imaging of GFP (neuron) and rhodamine (astrocytes) uncovered the contacts of astrocytes with the base or neck of the dendritic spines that already formed synaptic contacts, implying that astrocytic processes are not necessarily apposed to synaptic clefts but make contact with extrasynaptic domains of dendritic protrusions or spines. Supporting this view, astrocytic contact has been proven to be essential in maturation of the spines since the suppression of the Racl-dependent signal in astrocytes resulted in induction of longer filopodia-like dendritic protrusions, which are considered as immature dendritic spines [77], suggesting instructive roles of astrocytes in spine development. In addition, activation of EphA4 receptors on the dendritic spines by astrocytic ephrin-A3, a ligand for EphA4 receptor, maintains normal spine morphology in the hippocampus [78]. As well as inhibition of the EphA4 receptor independent of astrocyte, constitutive activation contacts decrease the lifetime of both preexisting and newly formed dendritic protrusions, suggesting that neuron-astrocytes contact is a key regulator for development and maturation of dendritic protrusions or spines. However, there is still a controversial issue with regard to other neuronal systems such as the cerebellum in which Bergmann glia extensions can fully encapsulate the synapses of parallel fiber/ Purkinje neurons [79]. The arborization of Bergmann glial processes is organized into discrete microdomains that respond independently to synaptic activity [80]. The mode of neuron-glia communications probably differs in different brain regions.

\section{Neuregulin 1-ErbB Receptor Signaling in Neuron-Glia Interaction}

From the viewpoint of the activity-dependent phenomenalism, neuregulin-1 (NRG1) is a signaling molecule of great interest. NRG1 protein activates the ErbB family of receptor tyrosine kinases including ErbB2, ErbB3 and ErbB4, and mediates cell-cell interaction in the nervous system and other organs such as breast and heart [71]. In addition, NRG1/ErbB signaling has been known to regulate the activation of ion channels and neurotransmitter receptors. A link between NRG1/ErbB signaling and mental disorders or neurodegenerative disorders has been strongly suggested [71, 81]. In particular, the implication of NRG1/ErbB signaling in pathogenesis of schizophrenia has been supported by numerous studies.

Our group has cloned $\mathrm{Nrg}$-1 gene by differential display of mouse brain exposed to different stimulation patterns of electrical activity [88]. NRG1 expression is consistently induced in an activity-dependent manner, and its proteolytic processing is also regulated by electrical activity [82]. Implication of NRG1-ErbB signaling in mental disorders is supported by extensive evidence showing that expression levels or functions of NRG1, ErbB3 or ErbB4 are significantly reduced in chronic 
schizophrenia patients [71, 81]. Moreover, a couple of studies have demonstrated that mice with reduced levels of NRG1 or ErbB4 exhibit behavioral abnormalities relevant to schizophrenia [71]. The changes in the expression level or functions of NRG1 have been shown to be critically involved in multiple physiological events throughout the CNS development, such as radial glia formation, neuronal migration, oligodendrocyte development, and myelination of axons [83], as well as NRG1-dependent expression of neurotransmitter receptors and glutamatergic synapse function.

Altered NRG1-ErbB signaling in these events possibly contributes to the onset of neuropsychiatric disorders. A number of histological studies of postmortem brain have shown anatomical abnormalities in several brain areas implicated in schizophrenia. For example, interstitial neurons, which are a remnant of the subcortical plate, are abnormally distributed in white matter of the prefrontal and temporal cortices of schizophrenia patients $[60,84]$. It is likely that NRG1-ErbB receptor signaling mediates the interaction between radial glia and migrating neurons of the subcortical plate. Thus, the defects in NRG1ErbB receptor signaling might result in an abnormal cortical connectivity and malfunction of glia (likely oligodendrocytes), which eventually leads to behavioral defects as observed in schizophrenia patients. Taken together, these studies suggest the potential link between NRG1ErbB signaling and the schizophrenia phenotypes. Supporting this, recent studies on transgenic mice defective in ErbB signaling have further demonstrated that loss of ErbB signaling leads to changes in morphology, number, and the in vivo function of oligodendrocytes. These transgenic mice also have increased levels of functional dopamine receptors $\left(D_{1^{-}}\right.$and $D_{2}$-like receptors) and dopamine transporters [85]. Moreover, they exhibit behavioral changes such that the transgenic mice are hypoactive, display an increased habituation and anxiety-like behavior, and also abnormal social behavior although their olfaction is normal [85].

NRG1-ErbB signaling in oligodendrocytes is now an emerging interest towards understanding the molecular basis of neuropsychiatric disorders such as schizophrenia or multiple sclerosis $[81,86,87]$. In adult CNS, multiple sclerosis lesions often fail to remyelinate, despite the presence of oligodendrocytes and oligodendrocyte precursor cells. The steady-state level of NRG1 or related growth factors on myelinated axons in the adult CNS is reduced below the level required for robust remyelination, particularly in demyelinated regions. Hence NRG1 signaling to myelinating glia must be presented directly by the axon whereas ectopic stimulation by soluble NRG1 might even have detrimental effects on myelination [71]. The temporal and quantitative regulation of NRG1 expression by neurons should be explored in a context of NRG1ErbB signaling in CNS since ErbB receptors are almost constitutively expressed in oligodendrocytes.

Our group has explored the electrical signal at CNS synapse as an intrinsic signal that triggers the cleavage of NRG1 type 1 . As a consequence of the cleavage, the $\mathrm{N}$ terminus domain of NRG1 is shed from the neuronal cell surface and functions as paracrine/autocrine signaling molecules to activate ErbB receptor signaling. We previously reported that electrical frequency of $\sim 50 \mathrm{~Hz}$ is a sufficient cue for the cleavage of NRG1 and the activation of ErbB signaling [82], implying the mechanism for the temporal and quantitative regulation of NRG1 expression at CNS synapses. Further studies using the NRG1 transgenic mice (e.g. cleavage-defective NRG1, GFPtagged NRG1) awaits the precise understanding of mechanism of spatiotemporal control of NRG1 cleavage in cortical connections.

It is intriguing to discuss that a significant number of cases of schizophrenia are accompanied by myelination defects. In fact, multiple sclerosis, metachromatic leukodystrophy, Nasu-Hakola disease and bipolar disorder exhibit both disrupted myelination and cognitive alterations [81]. Most of the studies strongly support the viewpoint that oligodendrocytes are the major recipient of NRG1-ErbB signaling and responsible for maintenance of normal neuronal connectivity and activity. When myelination or NRG1-ErbB signaling in oligodendrocytes is disturbed or altered, it would lead to altered perception and emotional states characteristic of schizophrenia.

Molecules involved in the synaptic communication may be fully elucidated by the benefits of various imaging modalities within the next decade. Fluorescent probes for physiological activity such as VSDs may exert their advantages to delineate the context of the molecular and structural interplay between neurons and glial cells in the whole neural network. Applications of VSDs in imaging of neuronal activity are described in the next section and reviews by Qiu et al. in this issue.

\section{Observation of Neuronal Activation by Voltage-Sensitive Dyes}

It is an advantage that optical recording with VSD gives direct two-dimensional pictures of multisite electroexcitation in real-time because the VSD converts the 
membrane potential of neurons and cardiac cells into optical properties such as fluorescent efficiency and/or absorption ratio. Historically, Tasaki et al. [89] found fluorescence intensity of some dye follows neuronal activation, and Cohen's group [90] made a big effort to establish the VSD method to record multisite membrane potentials without any electrodes. They built their original equipment by using a 144-element photodiode array and also synthesized a first VSD, Melocyanine 540. After 30 years, these pioneer researchers $[91,92]$ continue to develop dyes and equipment to expand the possibilities for VSDs.

In this period of time, we have developed a custom image sensor to enlarge special resolution as high as $>10,000$ sites, which was built using a monolithic semiconductor chip using metal oxide-semiconductor (MOS) technology [93, 94]. In 1998, we started producing and supplying the camera system we developed - named MiCAM. Fortunately, more than 100 researchers are using our system all over the world with their own specific optics and devices that are better suited to particular applications.

The following reviews practical experimental methods and advanced techniques in recent publications performed by the cameras we have developed.

\section{Dyes and Staining}

\section{Simple Way to First Success}

Many VSDs are listed in the catalog of molecular probes. 'Which dye is best?' is a reasonably simple question, but the answer is not so simple. Because every dye has its own specific properties for selective tissues and animals, you should try which dye is best for your purpose in practice. However, we can say that the RH-795 dye might become the first candidate of an initial trial because it can be dissolved directly into a water solution, stains many membranes and gives a large fluorescent signal for nerve excitation. The RH-795 is used simply by diluting $1 \mathrm{mg}$ of dye powder to $50-\mathrm{ml}$ solution and bathing specimen in the solution about 30 min with oxygen bubbling. The fluorescent signal is observed under the fluorescent microscope after stating and washing briefly. The RH-795 may provide reasonable results both in vivo and in vitro [94], also on vertebrate and invertebrate [95]. The RH-795 is supplied as a red powder in $1 \mathrm{mg}$; it should be used in a new vial within a day, excited by $530 \mathrm{~nm}$ wavelength light, and gives a red $(>590 \mathrm{~nm})$ fluorescent light. The signal is about $1 \%$ for the population spike in brain slices and in situ animals. But it has problems, i.e. the decline of fluorescence and it is costly to use every day. As a property of the dye, it can be washed out easily by both perfusion in chambers and circulation in animals, however the lifetime of RH-795 is too short to observe for $>30 \mathrm{~min}$.

\section{Stability in Vertebrate Brain Slices}

Di-4-ANEPPS is the best dye for a long stable recording for brain slices of rats, mice and guinea pigs. The problem is insolubility in water directly, because the dye itself shows strong lipid solubility. Accordingly, the powder of Di-4-ANEPPS should be solved by organic solvent first and diluted in a water solution with detergent. The following procedure is recommended to get the best signals: (1) the dye is dissolved into a 2:1 mixture of ethanol and $10 \%$ Cremophor EL (Sigma), a castor oil derivative, which is used as a dye stock solution; (2) the dye stock solution is mixed with a 1:1 mixture of solution and fetal bovine serum (Sigma) to a final dye concentration of 0.2 $\mathrm{mM}$ and is used as staining solution, and (3) the slice is stained with the staining solution for $25 \mathrm{~min}$ on a welloxygenized interface chamber and is rinsed with solution for at least $1 \mathrm{~h}$ before being used for recording. By using this procedure, a slice gives more than 100 shots of almost $1 \%$ optical signals for 2 or $4 \mathrm{~h}$ continuously with a small decline, like $10 \%$ in size. Di-4-ANEPPS powder is dark orange and slices stained by it get a very bright orange color, emitting strong fluorescence. Its excitation wavelength is $530 \mathrm{~nm}$ and emission wavelength is $580 \mathrm{~nm}$ and longer. Di-4-ANEPPS is good for staining brainstem [96], block brain [97] and isolated whole brain [98]. In addition, the dye indicates a very large signal, $>2 \%$, particularly in cardiac cells [99].

\section{From Single Cell to Whole Brain}

Di-2-ANEPPQ is a water-soluble and strong dye in all points for brain tissue. Its property is similar to RH-795, however it is less expensive and can be stored in a refrigerator for several weeks. Di-2-ANEPPQ provides a good signal-to-noise ratio for in situ rat brain recordings [100] and seems to have a smaller decline of fluorescence than RH-795. Di-2-ANEPPQ has another remarkable property, namely it can be applied inside a cell by internal perfusion to observe the single neuron activity of a brain slice. Figure 4 shows a single cell activity of CA 1 pyramidal cell stained with this dye from inside and voltage clamped [101]. Di-2-ANEPPQ can operate under the same optical setup as RH-795 and/or Di-4-ANEPPS, but it may give a better result with shorter wavelength excitation light, such as $480 \mathrm{~nm}$. 

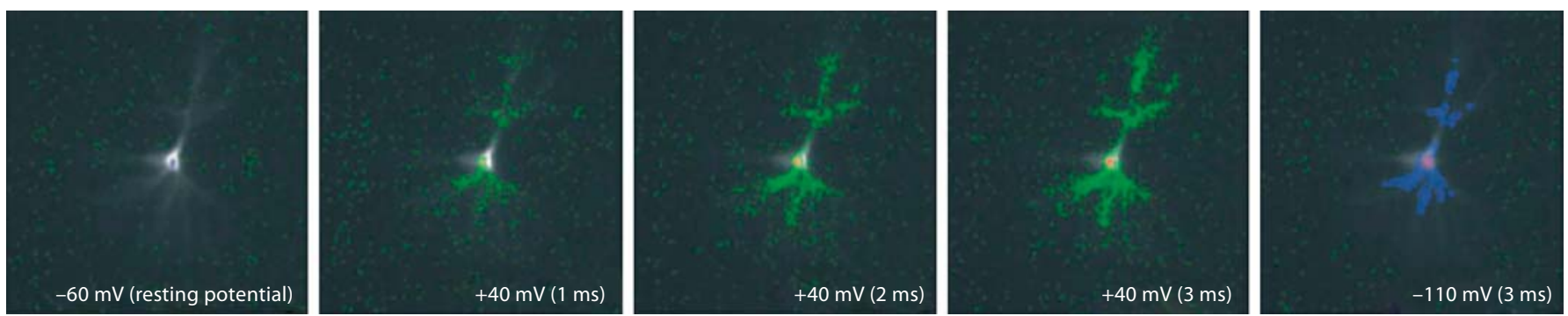

Fig. 4. Single neuron VSD imaging. Voltage-clamped CA1 pyramidal cell stained with Di-2-ANEPPQ by intracellular injection. Holding potential is $-60 \mathrm{mV}$, depolarized $50 \mathrm{mV}$ positive pulse and -50 negative pulse in a sequential order. CMOS imager MiCAM-UL was used at $1 \mathrm{~ms}$ sampling time and 32 times averaging repetitively.

Low Noise and High Stability for in situ Brain

Inevitable noise sources of an in situ brain recording are blood flow and heart beat. The point of RH-1691 is that excitation light wavelength is red $(630 \mathrm{~nm})$ and emission wavelength is dark red (700 $\mathrm{nm}$ and longer). Because the working wavelength of RH-1691 is close to blood transparent, the dye has less sensitivity for blood flow. Accordingly it is called the 'blue dye family'. One advantage is that the blue dye allows long-term recording [102] over $3 \mathrm{~h}$ with 250 shots of recording because of molecule stability and low toxicity [103].

\section{Equipment and Detection}

\section{What Is a Limitation to Detect?}

When a new experiment is designed, it is important to know the theoretical limitation of a method. In most VSD recordings, photon shot noise limits practical sensitivity and the signal-to-noise ratio. Principally, a photon generates an electron pair in a photodiode which is a light-sensitive site of the image sensor, and this process occurs according to probability distribution of the quantum theory which follows square law. Thus, the signal-to-noise ratio is better for higher intensity of light in square-root fashion, as shown in figure 5. In general, incoming light for an image sensor is proportional to: (1) illumination intensity; (2) fluorescent efficiency of dye and specimen; (3) a fourth of the numerical aperture of the objective lens; (4) square inverse of optical magnification; (5) the sampling time, and (6) pixel area of image sensor. When a fast and high-resolution recording is required, items 4 6 become smaller and smaller, then higher and improved items 1-3 should be provided. Practically, an 150-W halogen lamp and 530-nm band pass filter for illumination, a brain slice stained with Di-4-ANEPPS, $2 \times$ magnifica-

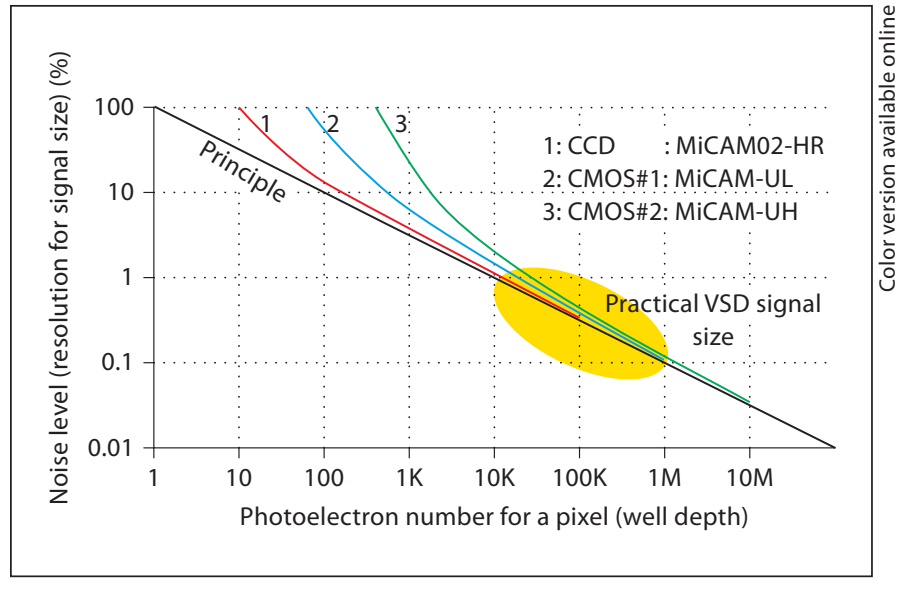

Fig. 5. Noise level versus light intensity projected on sensor pixel. It shows measured noise levels using three different image sensors. The black line shows theoretical noise level generated by photon shot noise. Curves 1, 2, and 3 show the noise level of CCD, CMOS1, and CMOS2 respectively. The shaded ellipse indicates the range of VSD signal size in a practical experiment of about $1-0.1 \%$.

tion NA $=0.3$ objective lens and $100 \mu \mathrm{m}^{2}$ pixel collects about 1 million photons in $0.1 \mathrm{~ms}$. For example, if target resolution is $10 \mu \mathrm{m}$ with the same setup, the sampling time should be shortened to $1 \mathrm{~ms}$ to keep the same photon income. However, if an improved lens of $10 \times \mathrm{NA}=0.5$ is provided, it may contribute to keep a 0.1-ms sampling time for the same target, because at a fourth of the ratio of NA, 0.5/0.3 gives a 7.7-fold brighter image. The optimized setup would be able to resolve both the sub-micrometer structure and sub-millisecond events simultaneously. It is no wonder that all of the biological conditions should be improved, including dyes, optics and cameras in order to achieve a supreme observation. 
Table 1. Comparison of specifications of camera systems from Brainvision Inc.

\begin{tabular}{|c|c|c|c|c|c|c|c|}
\hline Model & Type & Resolution & $\begin{array}{l}\text { Readout } \\
\text { time, ms }\end{array}$ & $\begin{array}{l}\text { Well } \\
\text { depth }\end{array}$ & $\begin{array}{l}\text { Readout } \\
\text { noise, e }\end{array}$ & $\begin{array}{l}\text { ADC } \\
\text { bits }\end{array}$ & $\begin{array}{l}\text { Sets } \\
\text { shipped }\end{array}$ \\
\hline MiCAM01 & CCD & $60 \times 90$ & 0.7 & $100 \mathrm{ke}$ & 200 & 12 & 47 \\
\hline MiCAM02-HS & CCD & $\begin{aligned} 60 & \times 90 \\
120 & \times 180\end{aligned}$ & $\begin{array}{l}1 \\
1.8\end{array}$ & $60 \mathrm{ke}$ & 60 & 12 & 10 \\
\hline MiCAM02-HR & CCD & $\begin{array}{c}60 \times 90 \\
120 \times 180\end{array}$ & $\begin{array}{l}2.2 \\
3.7\end{array}$ & $100 \mathrm{ke}$ & 40 & 12 & 30 \\
\hline MiCAM-UL & CMOS & $100 \times 100$ & 0.1 & $1 \mathrm{Me}$ & 240 & 14 & 20 \\
\hline MiCAM-UH & CMOS & $100 \times 100$ & 0.1 & $10 \mathrm{Me}$ & 900 & 14 & 10 \\
\hline
\end{tabular}

\section{Selection of Cameras}

The speculations of a camera include: (1) resolution: pixel number horizontally and vertically, (2) frame rate: sampling time for picture readout, (3) well depth: saturation photon number for a pixel, (4) readout noise: noise includes sensor and system, (5) ADC bits: signal resolution of a pixel, and so on. When a camera for observing structure is selected, items 1 and 4 could be the most important, but more attention should be paid to items 2, 3 and 5 if a camera for VSD is selected. Because of the description in a previous section, photon shot noise determines actual signal sensitivity, and it depends on how many photons accumulate in a pixel for sampling time. This means a camera with a larger well depth and faster readout time is better for VSD recording. On the other hand, from the viewpoint of biology, a camera with $>10$ million photons and faster than 0.1 ms readout is not necessary. Actually, 95\% of VSD experiments can be covered using a camera with 1 million photons and a 0.5 -ms sampling time. Also, almost $80 \%$ of signals can be captured by a slower than 2-ms sampling time. Table 1 shows specifications of the cameras we have developed. MiCAM01/02 is equipped with a charge-coupled device (CCD) image sensor and special drive circuit to achieve fast readout. A CCD has the advantage of a lower readout noise but also has disadvantages of smaller well depth and limited readout time. Sample experimental results using a MiCAM02-HR are shown in figure 6 , which are performed 16 times averaging to reduce photon shot noise. A complementary metal oxide semiconductor (CMOS)-active pixel sensor is almost the opposite to a CCD, thus is fast, has a large well depth, but is noisy. Even with the disadvantage of readout noise, CMOS is only one technology of realizing such a large well depth and speed. A MiCAM-UL camera in particular could be a reliable selection for general
VSD applications. A sample recording by MiCAM-UL is shown in figure 7 , which was recorded in a single trial. Looking towards the next generation system, by using the originally designed CMOS image sensor with 64,000 pixels and advanced readout circuits, a new camera system has been developed by our group. In addition, one can select cameras from (i) Redshirts Imaging, which, managed by Cohen, supplies highly sensitive CCD cameras for VSD, and (ii) Optical Imaging, which, initiated by Grinvald, provides fine-resolution cameras for VSD and intrinsic signals.

\section{Selection of Optics}

The numerical aperture of an objective is most important for VSD imaging because it gains brightness even at a similar illumination and sample. In general, a lower magnification objective has a smaller NA than a higher magnification objective. To overcome the brightness problem, an invention of tandem lens optics [104] contributes to observe both in situ brain and whole-size brain slices. A similar idea which uses a large objective and optical pass adapted to a special macro-microscope is the MVX10 from Olympus and THT2 from Brainvision [105]. For brain slice and/or cultured local circuit observation, a low magnification water-immersion objective lens is better than an air-gap lens, because it has a larger aperture and may reduce noise from water flow and vibration. We developed an $8 \times$ very long working distance water-immersion objective lens for this purpose, which is shown in figure 8 . If the observation target preserves a fine structure and retains local cell activity, a XLUMPLFL20 $\times$ W/Olympus and LWD16xWI/Nikon objective with a suitable upright microscope are recommended, because both realize a large NA and long working distance simultaneously. Another important optical component for all applications is a high-stability light 

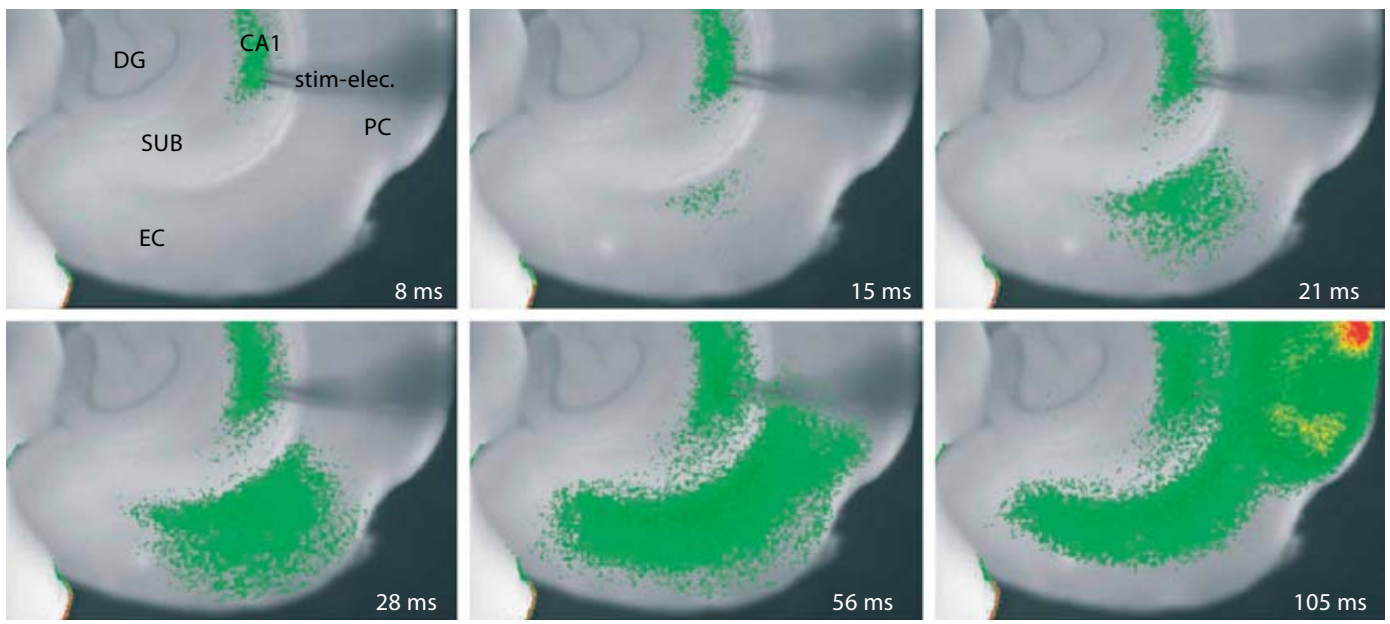

Fig. 6. High-resolution VSD recording performed by CCD (MiCAM02-HR). A brain slice of rat hippocampus and cortex stained with Di-4-ANEPPS was used. $384 \times 256$ pixel CCD image sensor working with $7 \mathrm{~ms}$ sampling time is able to take a high-resolution image which resolved about $10 \mu \mathrm{m}$. To improve the signal-to-noise ratio, 16 -shot recordings were averaged. Green portion optical signal is $0.5 \%$ and red portions indicate $1 \%$ and more.
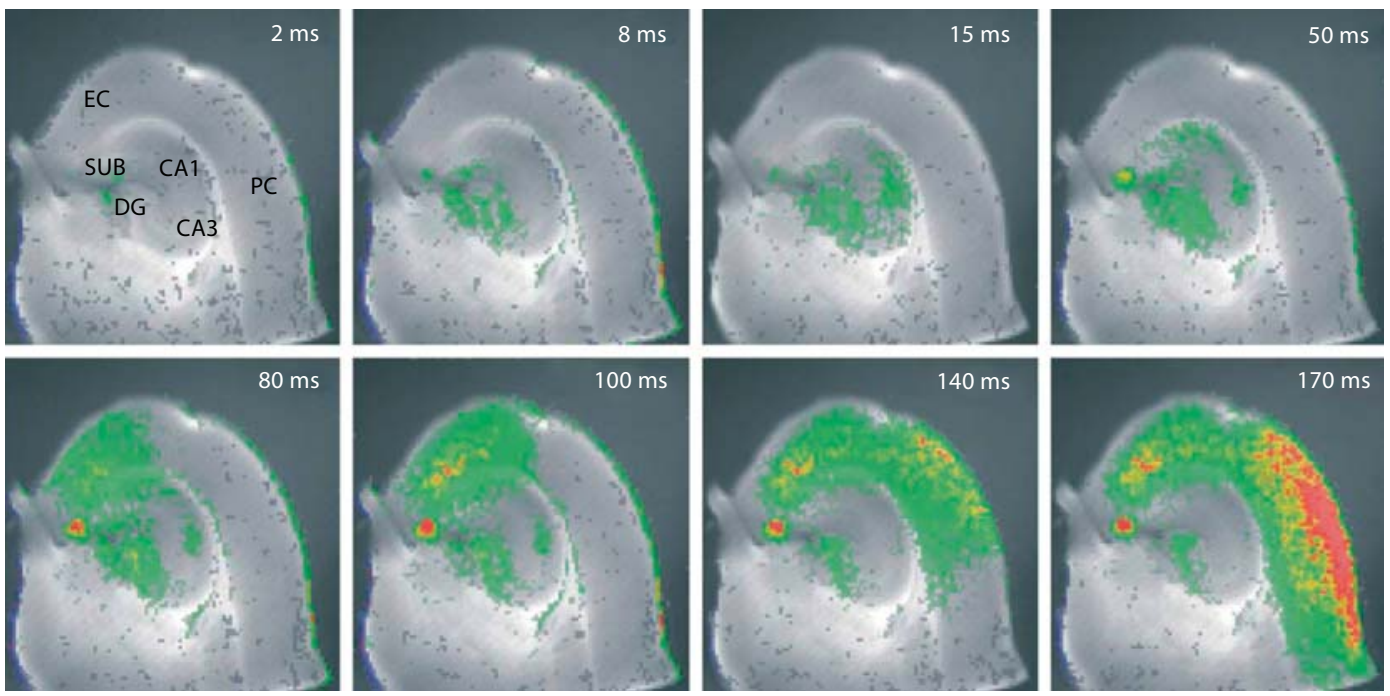

Fig. 7. Single-shot VSD recording performed by CMOS imager (MiCAM-UL). $100 \times 100$ pixel CMOS image sensor working with $1 \mathrm{~ms}$ sampling time is able to take enough signal-to-noise ratio image by single-shot recording. The same setup and slice from the same animal as in figure 6 were used.

source and its shutter. A halogen lamp with a band pass filter and a magnetic shutter is the most popular because the stability is better than other light sources, i.e. Hg, $\mathrm{M}-\mathrm{H}$ and lasers. Recently, a high-intensity light-emitting diode has been adapted to VSD recording [106]; it will be popular because of its size reduction, convenience and long lifetime.

\section{Signal Processing}

Both on- and offline signal processing provides better signal images and clear pictures, which can be contributed to new findings and publications. It is particularly important that online averaging and digital filter function enable the user to decide the next task of experiments. In practice, most slice recordings must be acquired 


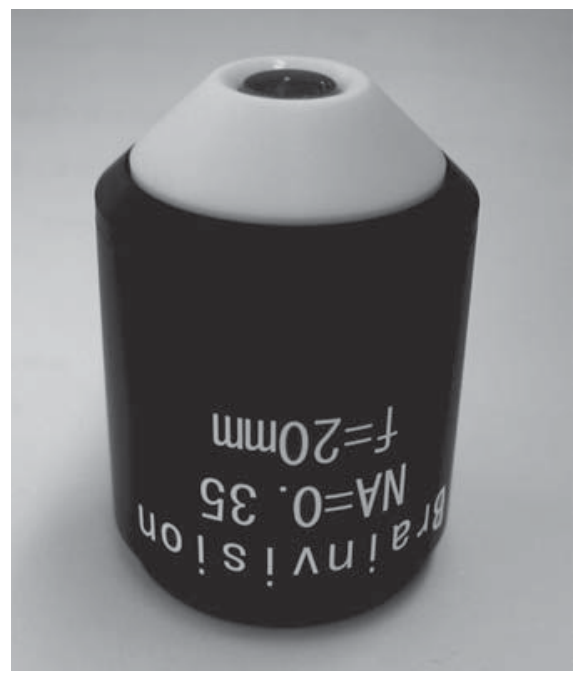

Fig. 8. A developed water-immersion objective lens. The objective lens is designed for optical recording. It can be mounted under a BX-50, THT microscope and other major microscopes. Magnification can be varied $3-10 \times$ by combination of projection lens. It has 6 -mm working distance in water. The top lens is surrounded by alumina ceramic body, protecting it from any solutions and salts.

several times and averaged to improve the signal-to-noise ratio to observe the change of excitation pattern and magnitude. Another example which might be crucial for online processing is removing heart beat noise of the in situ recording by using alternative add/sub according to synchronized stimulation sets. On the other hand, it is not so urgent, at least during experiments, to compensate for fluorescence declines, removing vibration of specimens by some accidental shock, precise comparison between pictures, and so on. These functions should be installed for offline processing to minimize the processing time of the computer and for the researcher's convenience. All camera systems in the future will be equipped with these processing functions by integrated software.

\section{Imaging of Excitation of Neuronal Circuits and Specific Brain Areas}

\section{Recent Publications Using Our MiCAM Camera}

\section{VSD Imaging with Multisite Electrodes: Observing} Oscillations in the Local Circuit

Mann et al. [107] have published beautiful results on gamma oscillations in the rat hippocampus by using two electrode array methods, i.e. the MED64 system (Alpha
Med Sciences Inc.) and VSD recording stained with Di-4ANEPPS. To elucidate the cellular and synaptic mechanisms underlying gamma frequency 'current' and 'rhythm' generation within the hippocampus, they analyzed fast network oscillations in vitro, using a combination of field recordings with planar multielectrode arrays, imaging with VSD, and recordings from individual pyramidal cells and interneurons. The data demonstrate that the fast cholinergically induced network oscillations are mediated by rhythmic perisomatic inhibition, which is synchronized by recurrent synaptic excitation. As a result, they concluded that AMPAR-mediated recurrent excitation was necessary for the synchronization of interneuronal discharge, which strongly supports a synaptic feedback model for the generation of hippocampal gamma oscillations.

\section{VSD Imaging for Isolated Brain: Finding Signal \\ Pathway}

De Curtis and colleagues [108] have demonstrated fantastic experiments on isolated guinea pig brain. They performed VSD, Di-2-ANEPPQ, imaging to observe local excitation in superficial and deep layers of the entorhinal cortex. They observed that the lateral olfactory tract-evoked hippocampus-mediated response is restricted to the medial entorhinal cortex and showed that the hippocampal output generated an extracellular current dip in layers V-VI, coupled with an excitatory postsynaptic potential in deep neurons. Their results show that superficial medial entorhinal cortex cells are inhibited by the hippocampal output via a feedforward pathway that prevents activity reverberation in the hippocampal-EChippocampal loop.

Kajiwara et al. [98] have measured excitation of entorhinal (EC), piriform (PC) and amygdaloid cortex (AC) by using Di-4-ANEPPS staining. They used their own developed high-resolution CCD system for observations and MiCAM01 as references. They investigated the propagation pattern of neural activity in olfactory cortices and observed two distinct pathways that convey neural activation evoked by olfactory nerve stimulation: a medial pathway from the $\mathrm{PC}$ to the $\mathrm{AC}$ and a lateral pathway from the PC to the lateral EC along the rhinal sulcus. Besides being activated directly via the medial pathway, the AC was activated a second time via activity that propagated from the lateral EC.

\section{VSD Imaging for in situ Brain: Visualizing}

Representation in Brain

Using an incredible VSD technique, Petersen and colleagues [109] succeeded in imaging free-moving animals 
by using a flexible optical fiber bundle. The fiber bundle consists of $300 \times 300$ thin fibers which are connected to the conventional fluorescent microscope at one end and the cortex surface at the other end. The optics covers a $3 \times 3 \mathrm{~mm}$ cortex area. They found that sensory responses evoked by passive whisker stimulation lasted longer and spread further across the barrel cortex in awake mice compared to anesthetized mice. Passively evoked sensory responses were large during behaviorally quiet periods and small during active whisking. However, as an exploring mouse approached an object while whisking, largeamplitude, propagating cortical sensory activity was evoked by active whisker touch. The results demonstrate differential processing of sensory input depending upon behavior.

Song and colleagues [110] published new findings about tone representation in the auditory cortical field, which were revealed by a well-established VSD imaging technique. They report the successful imaging of a rostral small field and intermediate zone and a ventral-to-dorsal frequency gradient in the intermediate zone. In their results it was found that ventral belt regions (VRB) can be subdivided into two areas - a ventrorostral field (VR) with properties similar to those reported for VRB, and a ventrocaudal field (VC) with novel properties. With increasing stimulus tone frequency, activation in VR shifted caudally while activation in VC shifted rostrally.

\section{Future Techniques for VSD Recording}

\section{FRET between YFP and VSD: A Way for Targeting}

VSD has long been considered a double-edged blade because of its efficient staining of cell membranes of all cell types with no discrimination of neurons or glial cells. This would be a major concern for VSD, especially when the target neurons are in the minority in the observing area and the intense signals from the glial cells or other neurons mask the signal from the targets. Iijima and colleagues [111] developed a clever and visually elegant method to overcome this problem by employing a targeted viral expression system and FRET [29] between YFP and VSD. Several days before the experiments, a modified rabies virus that conveys the YFP gene is applied to the downstream projecting area of a particular process so that the upstream neurons involved in this process would specifically transmit the rabies virus carrying the YFP gene and thus express YFP. However, because the YFP itself has no voltage sensitivity, subsequent application of VSD whose absorption wavelength fits the
YFP fluorescence selectively confers voltage-sensitive function to neurons that express YFP. They tested preliminary experiments and presented the data in major meetings [111]. In the future, the completed application study is expected.

\section{Dual Camera Recordings: A Way for Better Signal-to-Noise Ratio}

In normal application, Di-4-ANEPPS and Di-8ANEPPS emit a red fluorescent light at $600 \mathrm{~nm}$ or longer when excited by green light at $530 \mathrm{~nm}$, and the emission decreases by cell membrane depolarization. When excited by blue light at $480 \mathrm{~nm}$, the dye simultaneously emits both green $(<550 \mathrm{~nm})$ and red $(>590 \mathrm{~nm})$ fluorescence, and the green fluorescence emission increases by membrane depolarization whereas the red emission decreases [112]. Additional optics and camera devices are required so as to capture the red and the green emission separately and increase the ratio of the two signals at least twofold. This is expected to achieve about $50 \%$ of the signal-tonoise ratio. Furthermore, common phase noise that is often generated by higher illumination intensity or moving should in principle be eliminated. Especially in in situ brain and heart recordings, a dual camera option dramatically improves the signal-to-noise ratio because moving is largely a source of the undesired noise in in situ recordings.

\section{Fluorescent Lifetime Recording: A Way for \\ Quantitative Measurements}

The VSD method is a conventional way of estimating the membrane potential by relative changes in fluorescent intensity. However, it is probably the weakest point of VSD that it cannot be a measure of absolute membrane potential even though it shows relative local alterations in membrane voltage, because the measured signal is almost integral of four components: (1) single membrane potential; (2) ratio of related membrane to all membranes in a local site; (3) probability of staining with dye, and (4) efficiency of projection and correction of light. To calculate the real value of membrane potential by VSD, we should know how to manage all these factors, which may sound impossible in a practical sense. The quantitative measurement by VSD can be more realistic if it is examined by fluorescent lifetime measurement analysis. Actually it is possible to derive an equation to quantify the near absolute value of membrane potential based on the measured parameters such as intensity decay of VSD, lifetime of VSD and modulation of lifetime because modulation of fluorescent lifetime according to voltage is indepen- 
dent of the intensity. The key to a successful lifetime measurement is an apparatus to observe small fractions and very fast fluorescent decay which occurs in nanosecond time scales. We plan to develop a new CMOS image sensor which resolves $100 \mathrm{MHz}$ modulated light for this purpose.

\section{Conclusion}

Development of imaging techniques still continues to advance at a remarkable speed. Recent progress in in vivo optical imaging to monitor neuronal activities can be a useful screening process to design reagents that pharmacologically intervene in the progress of neuronal disorders that are mainly caused by loss of regulatory synaptic modification or dysfunctional neural circuits. In addition, as Ogasawara et al. describe in this issue, the simu- lation technique suggests the right direction of future research that bridges a gap between signal transduction pathways and information processing in the brain. Their success was achieved by the precise knowledge on the neural circuit of the cerebellum and also the optimal selection of molecular targets for the simulation. By combination of neural network simulation and imaging of molecules involved in neural communication, it will not take a long time before fluorescent-based optical imaging of brain functions becomes reality in biomedical research fields.

\section{Acknowledgements}

This work was supported in part by grants from the Ministry of Education, Culture, Sports, Science and Technology (MEXT) and Academic Frontier Project for Private Universities in Japan.

\section{References}

1 Yuste R, Denk W: Dendritic spines as basic functional units of neuronal integration. Nature 1995;375:682-684.

-2 Fisher M, Kaech SK, Knutti D, Matus A: Rapid actin-based plasticity in dendritic spines Neuron 1998;20:847-854.

>3 Okabe S, Kim HD, Miwa A, Kuriu T, Okado $\mathrm{H}$ : Continual remodeling of postsynaptic density and its regulation by synaptic activity. Nat Neurosci 1999;2:804-811.

4 Star EN, Kwiatkowski DJ, Murthy VN: Rapid turnover of actin in dendritic spines and its regulation by activity. Nat Neurosci 2002;5: 239-246.

5 Zheng L, Sheng M: Some assembly required: the development of neuronal synapses. Nat Rev Cell Biol 2003;4:833-841.

6 6 Hering H, Sheng M: Dendritic spines: structure, dynamics and regulation. Nat Rev Neurosci 2001;2:880-888.

7 Steward O, Levy WB: Preferential localization of polyribosomes under the base of dendritic spines in granule cells of dentate gyrus. J Neurosci 1982;2:284-291.

$\checkmark 8$ Eberwine J, Miyashiro K, Kacharmina JE, Job C: Local translation of classes of mRNAs that are targeted to neuronal dendrites. Proc Natl Acad Sci USA 2001;98:7080-7085.

$\checkmark 9$ Job C, Eberwine J: Localization and translation of mRNA in dendrites and axons. Nat Rev Neurosci 2001;2:889-898.

10 Kang H, Schuman EM: A requirement for local protein synthesis in neurotrophin-induced hippocampal synaptic plasticity. Science 1996;273:1402-1406.
11 Huber KM, Kayser MS, Bear MF: Role for rapid dendritic protein synthesis in hippocampal mGluR-dependent long-term depression. Science 2000;288:1254-1257.

12 Yamada S, Nelson VJ: Synapses: sites of cell recognition, adhesion, and functional specification. Annu Rev Biochem 2007;76:267294.

13 Mayford M, Baranes D, Podsypanina K, Kandel ER: The $3^{\prime}$-untranslated region of CaMKII $\alpha$ is a cis-acting signal for the localization and translation of mRNA in dendrites. Proc Natl Acad Sci USA 1996;93: 13250-13255.

14 Mori Y, Imaizumi K, Katayama T, Yoneda T, Tohyama M: Two cis-acting elements in the 3 ' untranslated region of $\alpha$-CaMKII regulate its dendritic targeting. Nat Nerosci 2000;3: 1079-1084.

15 Shan J, Munro TP, Barbarese E, Carson JH, Smith R: A molecular mechanism for mRNA trafficking in neuronal dendrites. J Neurosci 2003;23:8859-8866.

16 Martin KC, Zukin RS: RNA trafficking and local protein synthesis in dendrites: an overview. J Neurosci 2006;26:7131-7134.

17 Tiruchinapalli DM, Oleynikov Y, Kelic S, Shenoy SM, Hartley A, Stanton PK, Singer RH, Bassell GJ: Activity-dependent trafficking and dynamic localization of zipcode binding protein 1 and $\beta$-actin mRNA in dendrites and spines of hippocampal neurons. J Neurosci 2002;23:3251-3261.
18 Bassell GJ, Zhang H, Byrd AL, Femino AM, Singer RH, Taneja KL, Lifshitz LM, Herman IM, Kosik KS: Sorting of $\beta$-actin mRNA and protein to neurites and growth cones in culture. J Neurosci 1998;18:251-265.

19 Fujii R, Okabe S, Urushido T, Inoue K, Yoshimura A, Tachibana T, Nishikawa T, Hicks GG, Takumi T: The RNA binding protein TLS is translocated to dendritic spines by mGluR5 activation and regulates spine morphology. Curr Biol 2005; 15:587-593.

20 Zhang JL, Eom T, Oleynikov Y, Shenoy SM, Liebelt DA, Dictenberg JB, Singer RH, Bassell GJ: Neurotrophin-induced transport of a $\beta$-actin mRNP complex increases $\beta$-actin levels and stimulates growth cone motility. Neuron 2001;31:261-275.

21 Knowles RB, Sabry JH, Martone ME, Deerinck TJ, Ellisman MH, Bassell GJ, Kosik KS: Translocation of RNA granules in living neurons. J Neurosci 1996;16:7812-7820.

22 Krichevsky AM, Kosik KS: Neuronal RNA granules: a link between RNA localization and stimulation-dependent translation. Neuron 2001;32:683-696.

23 KieblerMA, HamrajI, VerkadelP, Kohrmann M, Fortes P, Marion RM, Ortin J, Dotti CG: The mammalian Staufen protein localizes to the somatodendritic domain of cultured hippocampal neurons: implications for its involvement in mRNA transport. J Neurosci 1999;19:288-297.

-24 Tang SJ, Meulemans D, Vazquez L, Colaco N, Schuman EM: A role for rat homolog of Staufen in the transport of RNA to neuronal dendrites. Neuron 2001;32:463-475. 
25 Eberhart DE, Malter HE, Feng Y, Warren ST: The fragile $\mathrm{X}$ mental retardation protein is a ribonucleoprotein containing both nuclear localization and nuclear export signals. Hum Mol Gen 1996;5:1083-1091.

-26 Comery TA, Harris JB, Willems PJ, Oostra BA, Irwin SA, Weiler IJ, Greenough WT: Abnormal dendritic spines in fragile $\mathrm{X}$ knockout mice: maturation and pruning deficits. Proc Natl Acad Sci USA 1997;94:54015404.

27 Hirokawa N: mRNA transport in dendrites: RNA granules, motors and tracks. J Neurosci 2006;26:7139-7142.

28 Kanai Y, Dohmae N, Hirokawa N: Kinesin transports RNA: isolation and characterization of an RNA-transporting granule. Neuron 2004;43:513-525.

29 Miyawaki A, Nagai T, Mizuno H: Engineering fluorescent proteins. Adv Biochem Eng Biotechnol 2005;95:1-15

- 30 Prasher DC, Eckenrode VK, Ward WW, Prendergast FG, Cormier MJ: Primary structure of the Aequorea victoria green-fluorescent protein. Gene 1992;111:229-233.

- 31 Miyawaki A, Nagai T, Mizuno H: Mechanisms of protein fluorophore formation and engineering. Curr Opin Chem Biol 2003;7: 557-562.

- 32 Köhrmann M, Luo M, Kaether C, DesGroseillers L, Dotti CG, Kiebler MA: Microtubule-dependent recruitment of Staufengreen fluorescent protein into large RNA-containing granules and subsequent dendritic transport in living hippocampal neurons. Mol Biol Cell 1999; 10:2945-2953.

-33 Steward O, Worley PF: Selective targeting of newly synthesized Arc mRNA to active synapses requires NMDA receptor activation. Neuron 2001;30:227-240.

34 Mercer J, Seperack PK, Strobel MC, Copeland NG, Jenkins NA: Novel myosin heavy chain encoded by murine dilute coat colour locus. Nature 1991;349:709-713.

- 35 Yoshimura A, Fujii R, Watanabe Y, Okabe S, Fukui K, Takumi T: Myosin-Va facilitates the accumulation of mRNA/protein complex in dendritic spines. Curr Biol 2006;16:23452351.

-36 Fujii R, Takumi T: TLS facilitates transport of mRNA encoding an actin-stabilizing protein to dendritic spines. J Cell Sci 2005;118: 5755-5765.

-37 Nimchinsky EA, Orberlander A, Svododa K: Abnormal development of dendritic spines in FMR1 knockout mice. J Neurosci 2001;21: 5139-5146.

- 38 Miyashiro KY, Beckel-Mitchener A, Purk TP, Becker KG, Barret T, Liu L, Carbonetto S, Weiler IJ, Greenough WT, Eberwine J: RNA cargoes associating with FMRP reveal deficits in cellular functioning in Fmrl null mice. Neuron 2003;37:417-431.
39 Antar LN, Afroz R, Dictenberg JB, Carroll RC, Bassell, GJ: Metabotropic glutamate receptor activation regulates fragile $\mathrm{X}$ mental retardation protein and Fmrl mRNA localization differentially in dendrites and at synapses. J Neurosci 2004;24:2648-2655.

40 Ceman S, O’Donnell WT, Reed M, Patton S, Pohl J, Warren ST: Phosphorylation influences the translation state of FMRP-associated polyribosomes. Hum Mol Gen 2003;12: 3295-3305.

41 Zalfa F, Giorgi M, Primerano B, Moro A, Di Penta A, Reis S, Oostra B, Bagni C: The fragile $\mathrm{X}$ syndrome protein FMRP associates with BC1 RNA and regulates the translation of specific mRNAs at synapses. Cell 2003; 112:317-327

42 Grossman AW, Aldridge GM, Weiler IJ, Greenough WT: Local protein synthesis and spine morphogenesis. J Neurosci 2006;26: 7151-7155

43 Pfeiffer EM, Huber KM: Current advances in local protein synthesis and synaptic plasticity. J Neurosci 2006;26:7147-7150.

-44 Miller S, Yasuda M, Coats J, Jones Y, Martone ME, Mayford M: Disruption of dendritic translation of CaMKII $\alpha$ impairs stabilization of synaptic plasticity and memory consolidation. Neuron 2002;36:507-519.

45 Aakalu G, Smith WB, Nguyen N, Jiang C Schumann EM: Dynamic visualization of local protein synthesis in hippocampal neurons. Neuron 2001;30:489-502.

$46 \mathrm{Ju}$ W, Morishita W, Tsui J, Gaietta G Deerinck TJ, Adams SR, Garner CC, Tsien RY, Ellisman MH, Malenka RC: Activity-dependent regulation of dendritic synthesis and trafficking of AMPA receptors. Nat Neurosci 2004;7:244-253.

47 Grooms SY, Noh KM, Regis R, Bassell GJ Bryan MK, Carroll RC, Zukin RC: Activity bidirectionally regulates AMPA receptor mRNA abundance in dendrites of hippocampal neurons. J Neurosci 2006;26:83398351

48 Steward O, Schuman EM: Compartmentalized synthesis and degradation of proteins in neurons. Neuron 2003;40:347-359.

49 Schuman EM, Dynes J, Steward O: Synaptic regulation of translation of dendritic mRNAs. J Neurosci 2006;26:7143-7146.

50 Colicos MA, Collins BE, Sailor MJ, Goda Y: Remodeling of synaptic actin induced by photoconductive stimulation. Cell 2001;107: 605-616.

51 Matsuzaki M, Honkura N, Ellis-Davies GCR, Kasai H: Structural basis of long-term potentiation in single dendritic spines. $\mathrm{Na}$ ture 2004;429:761-766.

52 Dillon C, Goda Y: The actin cytoskeleton: integrating form and function at the synapse. Annu Rev Neurosci 2005;28:25-55.

53 Lippman J, Dunaebsky A: Dendritic spine morphogenesis and plasticity. J Neurobio 2005;64:47-57.

-54 Matus A: Actin-based plasticity in dendritic spines. Science 2000;290:754-758.
55 Allison DW, Gelfand VI, Spector I, Craig AM: Role of actin in anchoring postsynaptic receptors in cultured hippocampal neurons: differential attachment of NMDA versus AMPA receptors. J Neurosci 1998; 18:24232436.

56 Krucker T, Siggins GR, Halpain S: Dynamic actin filaments are required for stable longterm potentiation in area CAl of the hippocampus. Proc Natl Acad Sci USA 2000;97: 6856-6861.

57 Lisman JE, Zabotinsky A: A model of synaptic memory: a CaMKII/PP1 switch that potentiates transmission by organizing an AMPA receptor anchoring assembly. Neuron 2001;31:191-201.

-58 Zhou Q, Xiao M, Nicoll RA: Contribution of cytoskeleton to the internalization of AMPA receptors. Proc Natl Acad Sci USA 2001;98: 1261-1266.

\$5 Fukazawa Y, Saitoh Y, Ozawa F, Ohta Y, Mizuno K, Inokuchi K: Hippocampal LTP is accompanied by enhanced F-actin content within the dendritic spine that is essential for late LTP maintenance in vivo. Neuron 2003; 38:447-460.

60 Gomez LL, Alam S, Smith KE, Horne E, Dell'Acqua ML: Regulation of A-kinase anchoring protein 79/150-cAMP-dependent protein kinase postsynaptic targeting by NMDA receptor activation of calcineurin and remodeling of dendritic actin. J Neurosci 2002;22:7027-7044.

61 Okamoto K, Nagai T, Miyawaki A, Hayashi Y: Rapid and persistent modulation of actin dynamics regulates postsynaptic reorganization underlying bidirectional plasticity. Nat Neurosci 2004;10:1104-1112.

-62 Matsuzaki M, Ellis-Davies GCR, Nemoto T, Miyashita Y, IIno M, Kasai H: Dendritic spine geometry is critical for AMPA receptor expression in hippocampal CA1 pyramidal neurons. Nat Neurosci 2004;4:1086-1092.

-63 Kacharmina JE, Job C, Crino P, Eberwine J: Stimulation of glutamate receptor protein synthesis and membrane insertion within isolated neuronal dendrites. Proc Natl Acad Sci USA 2000;97:11545-11550.

64 Ackermann M, Matus A: Activity-induced targeting of profilin and stabilization of dendritic spine morphology. Nat Rev Neurosci 2003;11:1194-1200.

65 Okabe S, Urushido T, Konno D, Okado H, Sobue K: Rapid redistribution of the postsynaptic density protein PSD-Zip45 (Homer 1c) and its differential regulation by NMDA receptors and calcium channels. J Neurosci 2001;21:9561-9571.

66 Sala C, Piech V, Wilson NR, Passafaro M, Liu G, Sheng M: Regulation of dendritic spine morphology and synaptic function by Shank and Homer. Neuron 2001;31:115-130.

67 Hering H, Sheng M: Activity-dependent redistribution and essential role of cortactin in dendritic spine morphogenesis. J Neurosci 2003;23:11759-11769. 
68 Segal M: Dendritic spines and long-term plasticity. Nat Rev Neurosci 2005;6:277-284.

-69 Haydon PG: GLIA: listening and talking to the synapse. Nat Rev Neurosci 2001;2:185193.

70 Volterra A, Meldolesi J: Astrocytes, from brain glue to communication elements: the revolution continues. Nat Rev Neurosci 2005;6:626-640

-71 Corfas G, Roy K, Buxbaum JD: Neuregulin 1-erbB signaling and the molecular/cellular basis of schizophrenia. Nat Neurosci 2004;7: 575-580.

-72 Panatier A, Theodosis DT, Mothet JP, Touquet B, Pollegioni L, Poulain DA, Oliet SH: Glia-derived D-serine controls NMDA receptor activity and synaptic memory. Cell 2006;125:775-784.

-73 Ventura R, Harris K: Three-dimensional relationships between hippocampal synapses and astrocytes. J Neurosci 1999;19:68976906

-74 Campbell RE, Tour O, Palmer AE, Steinbach PA, Baird GS, Zacharias DA, Tsien RY: A monomeric red fluorescent protein. Proc Natl Acad Sci USA 2002;99:7877-7882.

-75 Haber M, Murai KK: Reshaping neuron-glial communication at hippocampal synapses. Neuron Glia Biol 2006;2:59-66.

-76 Haber M, Zhou L, Murai KK: Cooperative astrocyte and dendritic spine dynamics at hippocampal excitatory synapses. J Neurosci 2006;26:8881-8891.

-77 Nishida H, Okabe S: Direct astrocytic contacts regulate local maturation of dendritic spines. J Neurosci 2007;27:331-340.

-78 Murai KK, Nguyen LN, Irie F, Yamaguchi Y, Pasquale EB: Control of hippocampal dendritic spine morphology through ephrinA3/EphA4 signaling. Nat Neurosci 2003;6: 153-160.

-79 Grosche J, Kettenmann H, Reinbach A: Bergmann glial cells form distinct morphological structures to interact with cerebellar neurons. J Neurosci Res 2002;68:138-149.

- 80 Grosche J, Matyash V, Moller T, Verkhratsky A, Reichbach A, Kettenmann H: Microdomains for neuron-glia interaction: parallel fiber signaling to Bergmann glial cells. Nat Neurosci 1999;2:139-143.

-81 Esper RM, Pankonin MS, Loeb JA: Neuregulins: versatile growth and differentiation factors in nervous system development and human disease. Brain Res Rev 2006;51:161175

82 Ozaki M, Itoh K, Miyakawa Y, Kishida H, Hashikawa T: Protein processing and release of neuregulin-1 are regulated in an activitydependent manner. J Neurochem 2004;91: 176-188.

83 Nave KA, Salzer JL: Axonal regulation of myelination by neuregulin 1. Curr Opin Neurobiol 2006;16:492-500.

84 Cannella B, Pitt D, Marchionni M, Raine CS: Neuregulin and erbB receptor expression in normal and diseased human white matter. J Neuroimmunol 1999;100:233-242.
85 Roy K, Murtie JC, El-Khodor BF, Edgar N, Sardi SP, Hooks BM, Benoit-Marand M Chen C, Moore H, O’Donnell P, Brunner D, Corfas G: Loss of ErbB signaling in oligodendrocytes alters myelin and dopaminergic function, a potential mechanism for neuropsychiatric disorders. Proc Natl Acad Sci USA 2007;104:8131-8136.

86 Harrison PJ, Weinberger DR: Schizophrenia genes, gene expression, and neuropathology: on the matter of their convergence. Mol Psychiatry 2005; $10: 40-68$.

87 Amanuma T, Ozaki M: Neurotrophic factor, neuregulin-1 and related molecules. Schizophr Front 2007;8:173-178

88 Ozaki M, Ichikawa M: Profile of genes regulated by specific patterns of electrical activities. Society for Neuroscience, Annual Meeting, Atlanta 2006, abstr 537.1.

89 Tasaki I, Watanabe A, Sandlin R, Carnay L: Changes in fluorescence, turbidity, and birefringence associated with nerve excitation. Proc Natl Acad Sci USA 1968;61:883-888.

90 Cohen LB, Salzberg BM, Davila HV, Ross WN, Landowne D, Waggoner AS, Wang CH: Changes in axon fluorescence during activity: molecular probes of membrane potential. J Membr Biol 1976;19:1-36.

91 Ross WN, Salzberg BM, Cohen LB, Grinvald A, Davila HV, Waggoner AS, Wang $\mathrm{CH}$ : Changes in absorption, fluorescence, dichroism, and birefringence in stained giant axons: optical measurement of membrane potential. J Membr Biol 1977;6:141-183.

92 Grinvald A, Salzberg BM, Cohen LB: Simultaneous recording from several neurones in an invertebrate central nervous system. $\mathrm{Na}$ ture 1977;14:140-142.

93 Ichikawa M, Iijima T, Matsumoto G: Realtime optical recording of neuronal activities in the brain; in Ono et al. (eds): Brain Mechanisms of Perception and Memory. Oxford, Oxford University Press, 1993, pp 639-647.

94 Iijima T, Witter MP, Ichikawa M, Tominaga T, Kajiwara R, Matsumoto G: Entorhinalhippocampal interactions revealed by realtime imaging. Science 1996;24:1176-1179.

$\$ 95$ Williamson R, Ichikawa M, Matsumoto G Neuronal circuits in cephalopod vision. Neth J Zool 1994;44:272-281.

-96 Onimaru H, Homma I: Developmental changes in the spatiotemporal pattern of respiratory neuron activity in the medulla of late fetal rat. Neuroscience 2005;131:969977.

97 Arata A, Ito M: Purkinje cell functions in the in vitro cerebellum isolated from neonatal rats in a block with the pons and medulla. Neurosci Res 2004;50:361-367.

98 Kajiwara R, Tominaga T, Takashima I: Olfactory information converges in the amygdaloid cortex via the piriform and entorhinal cortices: observations in the guinea pig isolated whole-brain preparation. Eur J Neurosci 2007;25:3648-3658.

99 Igor E, Vladimir N, Salama G: Optical imaging of the heart. Circ Res 2004;95:21-33.
100 Kaltenbach J, Zhang A: In vivo optical imaging of tone-evoked activity in the dorsal cochlear nucleus with a voltage-sensitive dye. J Neurosci Res 2004;78:908-917.

101 Ichikawa M, Tominaga T, Kawata T, Matsumoto G: Intrinsic and extrinsic optical signals in rat brain slices observed by high-speed imaging system. Society for Neuroscience, Annual Meeting, Washington 2003, abstr 759.5 .

102 Slovin H, Arieli A, Hildesheim R, Grinvald A: Long-term voltage-sensitive dye imaging reveals cortical dynamics in behaving monkeys. J Neurophysiol 2002;88:34213438

103 Civillico EF, Contreras D: Comparison of responses to electrical stimulation and whisker deflection using two different voltage-sensitive dyes in mouse barrel cortex in vivo. J Membr Biol 2005;208:171-82.

104 Ratzlaff EH, Grinvald A: A tandem-lens epifluorescence macroscope: hundred-fold brightness advantage for wide-field imaging. J Neurosci Methods 1991;36:127-137.

105 Tominaga T, Tominaga Y, Yamada H, Matsumoto G, Ichikawa M: Quantification of optical signals with electorophysiological signals in neural activities of Di-4ANEPPS-stained rat hippocampal slices. J Neurosci Methods 2000;102:11-23.

106 Nishimura M, Shirasawa H, Song WJ: A light-emitting diode light source for imaging of neural activities with voltage-sensitive dyes. Neurosci Res 2006;54:230-234.

107 Mann EO, Suckling JM, Hajos N, Greenfield SA, Paulsen O: Perisomatic feedback inhibition underlies cholinergically induced fast network oscillations in the rat hippocampus in vitro. Neuron 2005;45: 105-117.

108 Gnatkovsky V, de Curtis M: Hippocampusmediated activation of superficial and deep layer neurons in the medial entorhinal cortex of the isolated guinea pig brain. J Neurosci 2006;26:873-881.

109 Ferezou I, Bolea S, Petersen CC: Visualizing the cortical representation of whisker touch: voltage-sensitive dye imaging in freely moving mice. Neuron 2006;50:617629.

110 Nishimura M, Shirasawa H, Kaizo H, Song WJ: New field with tonotopic organization in guinea pig auditory cortex. J Neurophysiol 2007;97:927-932.

111 Inoue K, Ohara S, Ichijyo H, Kakei S, Iijima T: Development of rabies virus vectors for neuron-specific and trans-synaptic delivery of a foreign gene. Society for Neuroscience, Annual Meeting, Washington 2004, abstr 124.12.

112 Bullen A, Saggau P: High-speed, randomaccess fluorescence microscopy. II. Fast quantitative measurements with voltagesensitive dyes. Biophys J 1999;76:22722287. 